\title{
Incidence in South-west Scotland of hepatitis B surface antigen in the liver of patients with hepatocellular carcinoma
}

\author{
M. L. TURBITT, R. S. PATRICK, R. B. GOUdIE, AND W. M. BUCHANAN
}

From the University Department of Pathology, Glasgow Royal Infirmary, and the Department of Pathology, Stobhill Hospital, Glasgow, UK

SUMMARY A retrospective examination in South-west Scotland of formalin-fixed paraffin-embedded $\vec{N}$ liver tissue by an immunoperoxidase technique revealed hepatitis B surface antigen (HBsAg) in eigh $\vec{\sim}$ out of 81 cases $(10 \%)$ of primary hepatocellular carcinoma (PHC) and in four out of 82 cases $(5 \%)^{\circ}$ of cirrhosis. No positive staining was found in 112 controls without overt liver disease matched for age and sex. Unlike most previous studies showing an association between HBsAg and PHC, the present investigation was carried out in an area where HBs antigenaemia is infrequent and PHC is anD uncommon tumour. While possibly hepatitis infection is an important cause of PHC, the association between HBsAg and PHC could be due merely to activation by the tumour of latent virus B in $a_{\underline{\Phi}}^{\text {D. }}$ previously infected person.

By the use of serological tests for HBs antigenaemia an association between primary hepatocellular carcinoma and hepatitis B virus (HBV) infection has been demonstrated in several countries where both these conditions are common-for example, Uganda (Vogel et al., 1970), Taiwan (Tong et al., 1971), Senegal (Prince et al., 1975), Thailand (Chainuvati, et al., 1975), New Guinea (Woodfield et al., 1974), and Hong Kong (Lee, 1975). Previous reports from Hong Kong (Lee, 1972) and Nigeria (Smith and Francis, 1972) did not show this association.

Surveys carried out in areas with a low incidence of primary hepatocellular carcinoma also show an association between PHC and HBs antigenaemia, though all of the affected patients in the British study by Sherlock et al. (1970) were of Mediterranean stock while the three cases reported by Alpert and Isselbacher (1971) in the USA were Negro. The more recent survey of Reed et al. (1973), using the sensitive radioimmunoassay technique (RIA), showed $16 \%$ of a series of 32 British-born PHC patients to have $\mathrm{HBsAg}$ in the serum. No controls were included but the incidence of $\mathrm{HBsAg}$ in the general population was considered to be less than $1 \%$.

We have used an immunoperoxidase technique for staining $\mathrm{HBsAg}$ in histological sections of liver tissue stored as paraffin blocks and have made a retro-

Received for publication 23 May 1977 spective study of the incidence of the antigen in cases of PHC in south-west Scotland, where PHC is responsible for $0.46 \%$ of deaths (MacSween, 1974) and HBs antigenaemia is found by RIA in only oneo in 500 of the population (Wallace et al., 1972).

\section{Material and methods}

Paraffin blocks of sections of liver containing PHC obtained from 31 necropsies performed at Stobhill Hospital, Glasgow, during the years 1955 to 1973 and? from 40 necropsies at Glasgow Royal Infirmary from 3 1960 to 1973 were studied. Liver tissue obtained during surgical operation in 10 other cases of PHC were also studied. 'Normal' controls consisted of liver tissue from the next available necropsy or biopsy on a person of the appropriate age and sex $\frac{\vec{O}}{2}$ which showed little or no histological evidence of liver disease. Two normal controls were provided for each $\sigma$ Stobhill case. A control series of cirrhotic livers was N obtained from 28 necropsies performed at the Western Infirmary, Glasgow, and 54 at Glasgow Royal ${ }^{\omega}$ Infirmary from 1960 to 1974 . The age and sex dis- tribution in the PHC cases, controls, and cirrhotics are shown in Fig. 1. Table 1 shows the classification $\mathbb{\complement}$ of liver disease coexistent with the hepatocellular ${ }^{+}$ carcinoma and Table 2 the classification of the cirrhosis cases on the basis of histology.

The immunoperoxidase method of Burns (1975) 


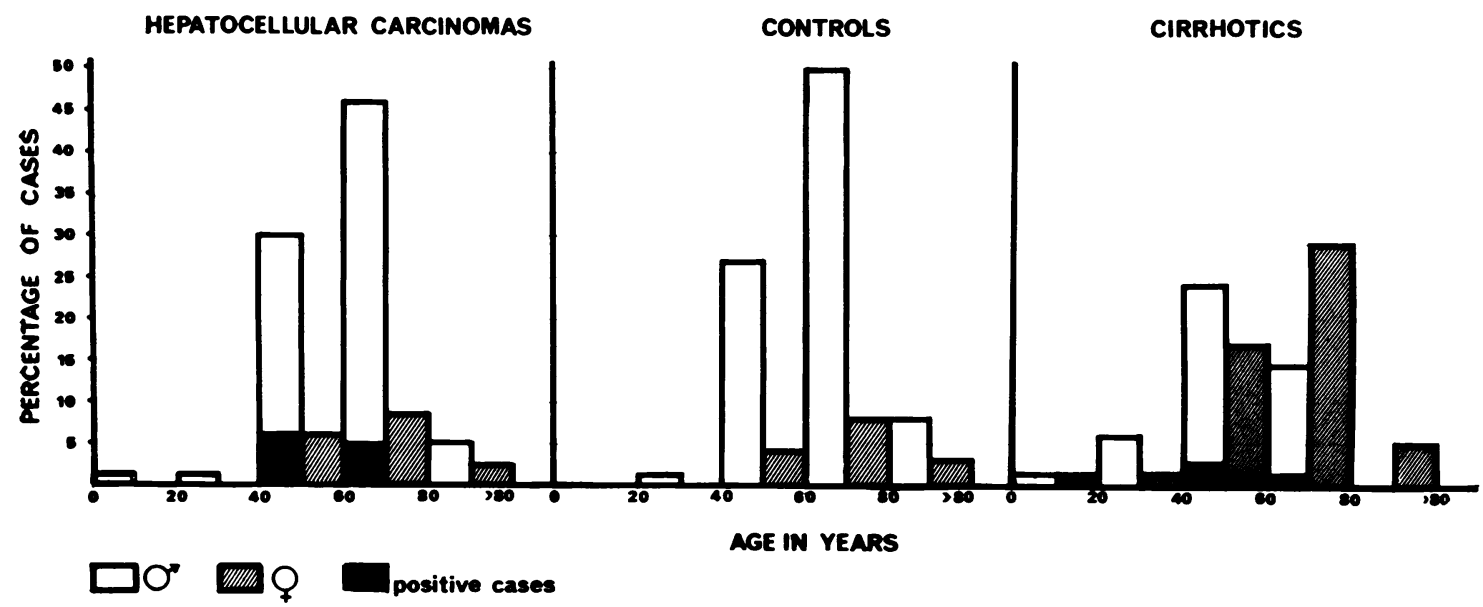

Fig. 1 Age and sex distribution of patients and controls.

Table 1 Liver disease in hepatocellular carcinoma cases

\begin{tabular}{lrl}
\hline Disease & No. & $\begin{array}{l}\text { No. HBsAg } \\
\text { positive }\end{array}$ \\
\hline Macronodular cryptogenic cirrhosis & 33 & 6 \\
Cirrhosis with haemochromatosis & 7 & - \\
Advanced primary biliary cirrhosis & 2 & 1 \\
No cirrhosis* & 32 & 1 \\
Not available for examination & 7 & - \\
\hline
\end{tabular}

* This group included 6 cases of nodular regenerative hyperplasia, 4 of cholangiohepatitis, 3 of cholestasis, 4 of portal fibrosis, 1 of early primary biliary cirrhosis, 1 of portal vein thrombosis, 2 of chronic venous congestion, 1 of fatty change, and 1 of siderosis. The histology of the other 9 was normal.

Table 2 Liver disease in cirrhotic control cases

\begin{tabular}{lll}
\hline Disease & No. & $\begin{array}{l}\text { No. HBs.Ag } \\
\text { positive }\end{array}$ \\
\hline Macronodular cryptogenic cirrhosis & 67 & 3 \\
Micronodular cirrhosis (including alcoholic) & 7 & - \\
Advanced primary biliary cirrhosis & 8 & 1 \\
\hline
\end{tabular}

was applied to 6- $\mu \mathrm{m}$ paraffin sections of liver with modifications to diminish background and endogenous peroxidase staining. Rabbit anti-HBsAg antiserum was obtained from Hoechst Pharmaceuticals and the other antisera and the peroxidase-antiperoxidase complex from Dakopatts (Mercia Diagnostics).

Ths specificity of all positive results was confirmed by the abolition of staining by prior absorption of the anti-HBsAg antiserum with human serum containing HBsAg but not with normal human serum. In some experiments $\mathrm{HBsAg}$ purified by the method of Burrell (1975) was also used.

\section{Results}

Table 3 shows that liver cells were positively stained

Table 3 HBsAg detected by immunoperoxidase in hepatocellular carcinoma patients, normal controls, and cirrhotics

\begin{tabular}{lrl}
\hline Group & No. & $\begin{array}{l}\text { No. } \mathrm{HBsAg} \\
\text { positive }\end{array}$ \\
\hline Primary hepatocellular carcinoma & 81 & 8 \\
Controls & 112 & - \\
Cirrhotics & 82 & 4 \\
\hline
\end{tabular}

Note. $\chi^{2}$ (PHC and controls) $=9.2(\mathrm{P}<0.01)$.

for $\mathrm{HBsAg}$ in eight out of $81(9.8 \%)$ cases of hepatocellular carcinoma and not in any of 112 normal controls $(P<0.01)$. All the positive PHC results were in male necropsy cases with no obvious age bias with respect to the population studied (Fig. 1). In seven of the eight positive PHC cases the liver unaffected by tumour was cirrhotic. The liver in the remaining case showed evidence of cholangitis, probably the result of bile duct obstruction by the tumour. HBsAg positive cells were found both in the tumour and in the surrounding tissue in three cases (Table 4). In each of these staining was less intense in the tumour. Positive staining was also found in four out of 82 cases of cirrhosis without tumour $(4.9 \%)$, two male and one female macronodular cirrhosis cases, and one male with advanced biliary cirrhosis. The staining was similar to that in the PHC cases but usually less intense.

The livers of the eight hepatocellular carcinoma cases and the four cirrhotics were consistently 
Table 4 Details of cases with HBsAg in liver

\begin{tabular}{|c|c|c|c|c|c|c|}
\hline \multirow[t]{2}{*}{ Case } & \multirow[t]{2}{*}{ Nationality } & \multirow[t]{2}{*}{ Age (years) } & \multirow[t]{2}{*}{ Sex } & \multirow[t]{2}{*}{ Liver disease } & \multicolumn{2}{|c|}{ Distribution of $\mathrm{HBs} A \mathrm{~g}$} \\
\hline & & & & & Liver & Carcinoma \\
\hline 1 & British & 43 & $\mathbf{M}$ & PHC + PBC & + & + \\
\hline 2 & British & 57 & $\mathbf{M}$ & PHC + macronodular cirrhosis & + & - \\
\hline 3 & British & 50 & $\mathbf{M}$ & PHC + macronodular cirrhosis & + & + \\
\hline 4 & Chinese & 43 & $\mathbf{M}$ & PHC + macronodular cirrhosis & + & + \\
\hline 5 & British & 69 & $\mathbf{M}$ & PHC + cholangitis & + & - \\
\hline 6 & British & 77 & $\mathbf{M}$ & PHC + macronodular cirrhosis & + & - \\
\hline 7 & British & 59 & $\mathbf{M}$ & PHC + macronodular cirrhosis & $\div$ & - \\
\hline 8 & British & 64 & $\mathbf{M}$ & PHC + macronodular cirrhosis & + & _ \\
\hline 9 & British & 60 & $\mathbf{F}$ & Macronodualr cirrhosis & + & \\
\hline 10 & British & 59 & $\mathbf{M}$ & Macronodular cirrhosis & + & \\
\hline 11 & British & 72 & $\mathbf{M}$ & Macronodular cirrhosis & + & \\
\hline 12 & British & 53 & $\mathbf{M}$ & Advanced PBC & + & \\
\hline
\end{tabular}

positive when stained with antiserum to $\mathrm{HBsAg}$ (with or without absorption by normal human serum) and negative when the antiserum was absorbed with HBsAg-containing serum or with purified HBsAg. Figure 2a shows the immunoperoxidase reaction in a typical group of positive cells in liver adjacent to hepatoma. Figure $2 b$ shows the same area in an adjacent section stained with adsorbed antiserum indicating the specificity of the reaction. Figure 3 shows the immunoperoxidase reaction in positive cells in an area of tumour. The intensity and distribution of the staining varied widely in the eight cases. In most there were substantial areas of liver tissue with large numbers of positive cells, while elsewhere in the same section there were scattered solitary positive cells. The appearance of a positively stained hepatocyte is quite characteristic, the stain deposit being finely granular

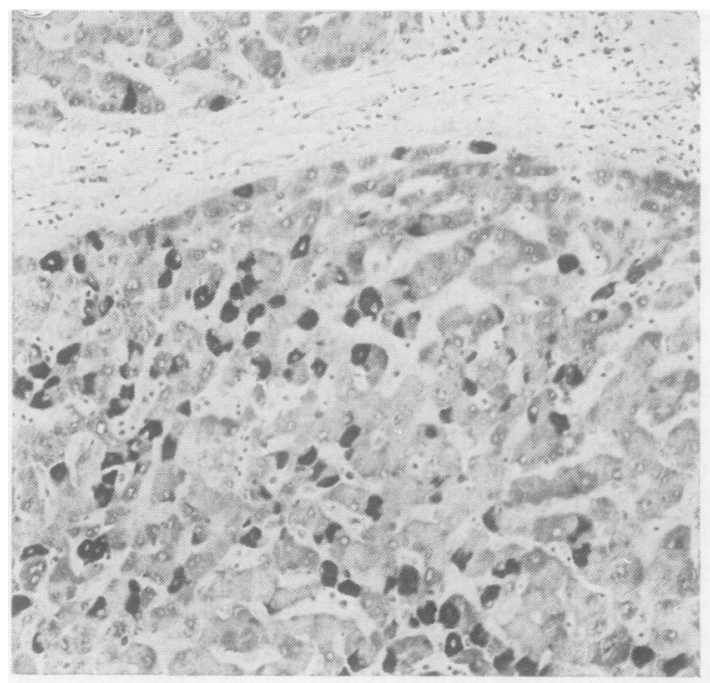

(a) with a strong brown coloration contrasting with the. pale background of the surrounding negative cells. $\overrightarrow{\mathrm{N}}$ In some instances the staining reaction appears to filithe entire cytoplasm while in others it is localised in discrete and often sharply demarcated areas. There iso no nuclear staining.

\section{Discussion}

The sensitivity of the immunoperoxidase staining of liver for detecting hepatitis B infection is unknown. Certainly it is more sensitive than the orcein teste (Shikata et al., 1974), which we also carried out in of our cases and which gave fewer and less definate positive results.

In our retrospective study we were unable to carry out tests on the sera of many patients. We did so in five cases, and it is of interest that two with HBs anti- $-\frac{\mathrm{D}}{2}$

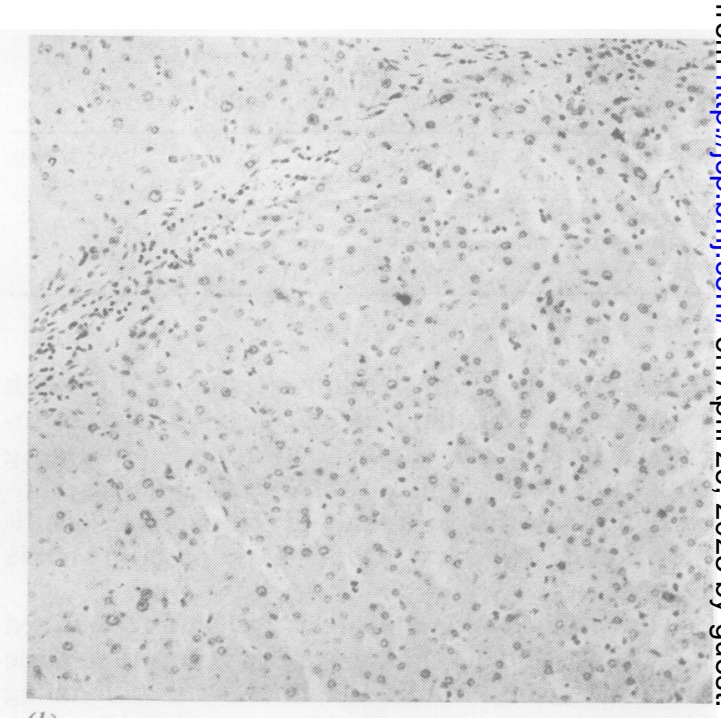

Fig. 2 Immunoperoxidase staining (black) of cirrhotic liver near primary hepatocellular carcinoma (a) using antiserum to $\mathrm{HBs} \mathrm{Ag}$, (b) using the same antiserum previously absorbed with $\mathrm{HBs} \mathrm{Ag}$. 


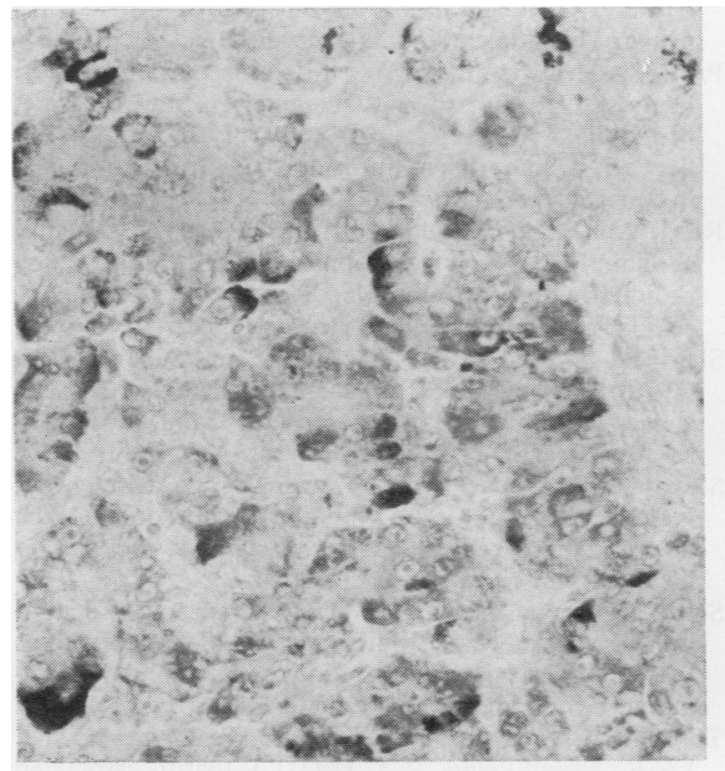

(a)

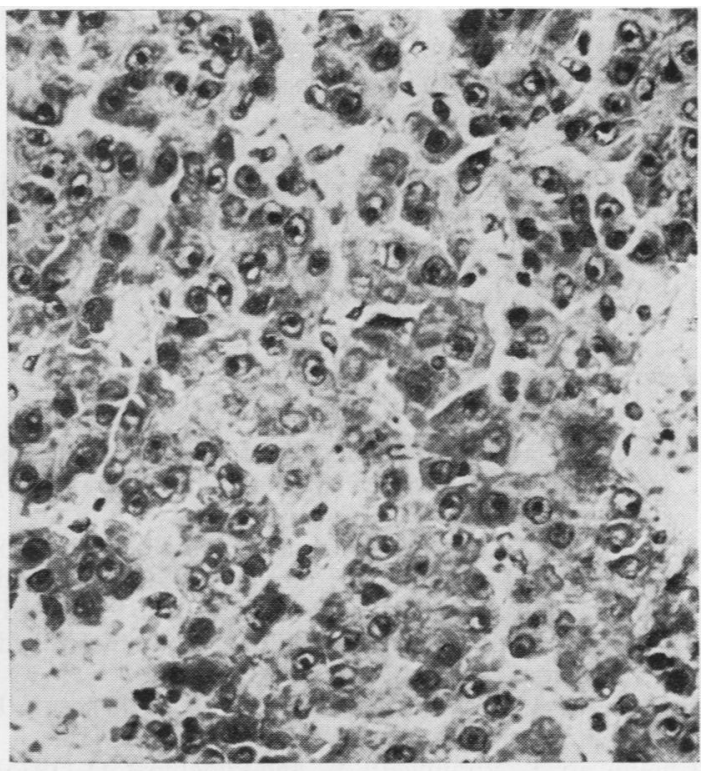

(b)

Fig. 3 Primary hepatocellular carcinoma showing (a) irregular pattern of positive immunoperoxidase staining of HBsAg in a minority of tumour cells; (b) same field stained by haematoxylin and eosin.

genaemia by RIA were the only two with positive cells by immunoperoxidase. In an unpublished study of 100 necropsies in which serum was tested for HBsAg by RIA and paraffin sections of liver by immunoperoxidase no positive cases were found. Six livers showed nonspecific staining with the characteristic appearance of HBsAg. But this was abolished by absorption with normal human serum and not with purified $\mathrm{HBsAg}$, presumably because the antiserum contained a second antibody against a component of normal human serum.

We found significantly more HBsAg in PHC patients than in normal controls, confirming the association between $\mathrm{HBV}$ and PHC previously shown most clearly in tropical countries. There are at least three explanations of the nature of this association.

Firstly, that the tumour is the result of infection with the virus through a chain of events from chronic viral hepatitis to cirrhosis and cirrhosis to PHC. However, we have not found HBsAg significantly more often in patients with PHC in cirrhotic livers $(16 \%)$ than in those with PHC in non-cirrhotic liver, $(3 \%)$. This may be attributed to the relatively small number of cases but it is in agreement with both Reed et al. (1973) in England and Prince et al. (1975) in Senegal. The fact that cases of PHC associated with HBsAg arise with some frequency in non-cirrhotic liver is not explained by this hypothesis.
A second possible explanation is that the virus has a direct oncogenic effect on liver cells. This is not supported by our finding of no significant increase in frequency of $\mathrm{HBsAg}$ in cirrhosis complicated by PHC (10\%) compared with uncomplicated cirrhosis $(5 \%)$.

Conceivably two mechanisms may operate-that is, infection with hepatitis virus may progress to macronodular cirrhosis, which may later be complicated by PHC, and continuing infection may also result in PHC in an otherwise normal liver. An alternative explanation of our findings could be that PHC activates latent hepatitis B virus with production of $\mathrm{HBsAg}$ in infected cells. Consistent with that is an unpublished observation that $7.5 \%$ of normal people in South-west Scotland have antibody to HBsAg by RIA, indicating previous and perhaps latent virus $B$ infection. This is similar to the incidence of $\mathrm{HBsAg}(10 \%)$ in our local PHC patients (by immunoperoxidase). It is noteworthy that in countries where hepatitis B infection is widespread activation of latent virus by PHC could also explain the common occurrence of $\mathrm{HBs}$ antigenaemia in patients with this disease.

The fact that the virus is sometimes restricted to the non-neoplastic liver and is sometimes also present in the tumour is unexplained. A recent study of the incidence of antibody to hepatitis B core antigen in PHC patients (Maupas et al., 1975) suggests there 
may be continuous production of core antigen but not surface antigen in the tumour cells of some patients. We hope to investigate the incidence of core antigen in the livers used in this study.

We thank the Distillers Company for supporting this study, Dr R. N. M. MacSween for providing material from cirrhotic livers without PHC, and Dr C. Burrell for the sample of purified HBsAg.

\section{References}

Alpert, E., and Isselbacher, K. J. (1971). Hepatitisassociated antigen and hepatoma in the U.S. (Letter). Lancet, 2, 1087.

Burns, J. (1975). Background staining and sensitivity of the unlabelled antibody enzyme (PAP) method. Comparison with the peroxidase labelled antibody sandwich method using formalin fixed paraffin embedded material. Histochemistry, 43, 291-294.

Burrell, C. J. (1975). Host components in hepatitis B antigen. Journal of General Virology, 27, 117-126.

Chainuvati, T., Viranuvatti, V., and Pongpipat, D. (1975). Relationship of hepatitis B antigen in cirrhosis and hepatoma in Thailand. Gastroenterology, 68, 12611264.

Lee, A. K. Y. (1972). Australia antigen in Hong Kong Chinese (Letter). Lancet, 1, 1119-1120.

Lee, A. K. Y. (1975). Hepatitis B antigen and autoantibodies in chronic liver diseases in Hong Kong. Australian and New Zealand Journal of Medicine, 5, 235-239.

MacSween, R. N. M. (1974). A clinicopathological review of 100 cases of primary malignant tumours of the liver. Journal of Clinical Pathology, 27, 669-682.

Maupas, P., Larouzé, B., London, W. T., Werner, B., Millman, I., O'Connell, A., and Blumberg, B. S. (1975).
Antibody to hepatitis-B core antigen in patients withô primary hepatic carcinoma. Lancet, 2, 9-11.

Prince, A. M., Szmuness, W., Michon, J., Demaille, J., Diebolt, G., Linhard, J., Quenum, C., and Sankale,o M. (1975). A case/control study of the associationo between primary liver cancer and hepatitis B infection $\overline{\bar{c}}$ in Senegal. International Journal of Cancer, 16, 376-383.

Reed, W. D., Eddleston, A. L. W. F., Stern, R. B., and 0 Williams, R. (1973). Detection of hepatitis B antigen byô radioimmunoassay in chronic liver disease and hepato- $\overrightarrow{0}$ cellular carcinoma in Grèat Britain. Lancet, 2, 690-694.:

Sherlock, S., Fox, R. A., Niazi, S. P., and Scheuer, P. J. (1970). Chronic liver disease and primary liver-cello cancer with hepatitis-associated (Australia) antigen in serum. Lancet, 1, 1243-1247.

Shikata, T., Uzawa, T., Yoshiwara, N., Akatsuka, T.,. and Yamazaki, S. (1974). Staining method of Australia $\vec{N}$ antigen in paraffin sections. Japanese Journal of Experimental Medicine, 44, 25-36.

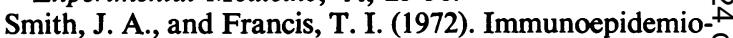
logical and in vitro studies of possible relationships between Australia antigen and hepatocellular carci- noma. Cancer Research, 32, 1713-1720.

Tong, M. J., Sun, S. C., Schaeffer, B. T., Chang, N. K., Lo, K. J., and Peters, R. L. (1971). Hepatitis associated antigen and hepatocellular carcinoma in Taiwan. Annals of Internal Medicine, 75, 687-691.

Vogel, C. L., Anthony, P. P., Mody, N., and Barker, L. $\mathbb{F} . \overrightarrow{0}$ (1970). Hepatitis associated antigen in Uganden $\mathrm{N}$ patients with hepatocellular carcinoma. Lancet, 2, 62 . 624.

Wallace, J., Milne, G. R., and Barr, A. (1972). Total screening of blood donations for Australia (hepatitiso associated) antigen and its antibody. British Medical0 Journal, 1, 663-664.

Woodfield, D. G., Endo, Y., and Matsuhashi, T. (1974) $\stackrel{2}{\overrightarrow{7}}$ Primary liver cancer, alpha ${ }_{1}$ fetoprotein and hepatitis $\mathrm{B}_{7}$ antigen in Papua New Guinea. Australian and New Zealand Journal of Medicine, 4, 3-7. 